\title{
APLICACIÓN DE LA TEORÍA DE LOS ACTOS PROPIOS RESPECTO DE ESCRITURA PÚBLICA QUE NIEGA EL CARÁCTER REMUNERATARIO DE LA GRATIFICACIÓN
}

\section{APPLICATION OF THE THEORY OF ESTOPPEL REGARDING A PUBLIC INSTRUMENT THAT DENIES THE REMUNERATORY NATURE OF THE GRATIFICATION}

\author{
RENÉ MAURICIO DEL REAL MORALES* \\ Universidad de Chile
}

\begin{abstract}
RESUMEN: Este comentario de jurisprudencia analiza la procedencia de la aplicación de la doctrina de los actos propios en materia laboral, en particular en relación al caso del trabajador que exigió como parte de la base de cálculo de la indemnización por término del contrato, la "gratificación" que el empleador pagaba informalmente al trabajador, y respecto del cual este último firmó escritura pública, señalando que se trataba de un aporte entregado de "forma voluntaria y graciosa". A partir de este caso, el autor analiza si se puede descartar por completo la aplicación de la doctrina de los actos propios en materia laboral, tomando en consideración que dicha teoría encuentra su fundamento en la buena fe más que en la autonomía de la voluntad.
\end{abstract}

PALABRAS CLAVE: Teoría de los Actos Propios; autonomía de la voluntad; remuneración; gratificación; irrenunciabilidad de los derechos laborales

ABSTRACT: This comment of jurisprudence analyzes the origin of the applicability of estoppel in labor matters, particularly in relation to the case of a worker who demanded as part of the basis for calculating the compensation for termination of the contract, the "gratification" the employer paid the worker informally, and for which the latter signed a public document, noting that it was a contribution given in a "voluntary and liberally way." From this case, the author analyzes whether is posible to completely rule out the application of estoppel in labor matters, taking into consideration that this theory is founded on good faith rather than autonomy.

KEY WORDS: Estoppel; autonomy; remuneration; gratification; irrevocability of labor rights

Interesa la sentencia que pasaremos a analizar, por cuanto zanja la disputa referida a la aplicación de la denominada "Teoría de los actos propios" en materia laboral, y su vinculación con el principio de la irrenunciabilidad de los derechos de los trabajadores. En este punto, advertimos que la conciliación entre ambos conceptos no había sido fácil, ya que si bien el contrato de trabajo, como cualquier otro, debe aplicarse y ejecutarse de buena fe por las partes, podría discutirse si las aparentes conductas contradictorias del trabajador, que nos llevarían a concluir que está obrando de mala fe, se derivan del interés del empleador de restarle valor a sus derechos. En este punto, examinaremos algunas de las posturas de la doctrina al respecto,

\footnotetext{
* Abogado y ayudante de la cátedra Historia Institucional de Chile de la Universidad de Chile. Actualmente cursa Magíster de Derecho del Trabajo y Seguridad Social de dicha casa de estudios. Contacto: renedelreal@yahoo.es.
} 
definiendo la que consideraremos más aplicable a este tipo de situaciones, y en especial, a la de la resolución en comento.

Entrando en materia, la aludida sentencia se pronunció especialmente de la inclusión, en el cálculo de la indemnización de años de servicios de la actora, del beneficio denominado "gratificación", que su empleador le enteraba informalmente mediante transferencias directas a su cuenta bancaria. En la especie, la demandada alegaba que dicho estipendio debía excluirse de la citada base, por cuanto la demandante había suscrito, junto a otros trabajadores, una escritura pública que indicaba que lo otorgaba "de forma voluntaria y graciosa", en la medida que los excedentes de la empresa lo permitiesen. De esta forma, la empresa afirmó que la gratificación no constituiría remuneración, sino que una mera liberalidad.

En la instancia, el sentenciador estimó que el aludido monto no era remuneración, aplicando la denominada "Teoría de los Actos Propios". En este punto, señaló que la actora había infringido la buena fe, aprovechándose de una situación que le generó beneficios en su favor, en circunstancias que "...durante toda su trayectoria adoptó una conducta acorde a los planteamientos que su empleador determinó, e incluso acudió en defensa de ellos ante estrados en decisiones de igual naturaleza". ${ }^{1}$

Respecto de esta sentencia, la actora dedujo recurso de nulidad, que fue rechazado íntegramente por la Iltma. Corte de Apelaciones de Santiago, por estimar que no había infracción de ley en su dictación y que la apreciación de la prueba fue la correcta. ${ }^{2}$

A su turno, la actora dedujo recurso de unificación de jurisprudencia, asilándose en que existían distintas interpretaciones del tema. En contraposición a la decisión adoptada en la causa, la actora presentó una resolución que señalaba lo contrario, es decir, que el estipendio sí constituía remuneración. Agregando que no podía aplicarse la teoría de los actos propios en materia laboral, ya que ello importaría "...acoger principios que son propios en materia civil, como lo es la autonomía de la voluntad, la que se encuentra totalmente erradicada en materia laboral...". 3

Pues bien, al decidirse el asunto en controversia, la Corte Suprema acogió el recurso de la actora, refiriendo que la citada gratificación había sido enterada por "...la demandada de manera regular y permanente durante la relación laboral" ${ }^{4}$ y que por ende, tenía el carácter de remuneración. Añadiendo que la suscripción de la escritura pública no obstaba lo anterior, toda vez que "...la autonomía de la voluntad consagrada en el artículo 1.545 del Código Civil, e invocada por la parte empleadora como defensa, no puede aplicarse al derecho laboral para perjudicar a los trabajadores" 5

Finalmente, puntualiza que "...los principios tradicionales del derecho privado no son aplicables de modo absoluto en el campo del derecho laboral, desde que intervienen principios proteccionistas a favor del operario, entre ellos, la irrenunciabilidad de los derechos, como principio de carácter general, que impide que el trabajador por la vía del acuerdo renuncie a aquello que le beneficia, por cuanto ello tornaría ineficaz el Derecho Laboral".

\footnotetext{
${ }^{1}$ Soissa con Caja de Ahorros de Empleados Públicos (2014).

2 Soissa con Caja de Ahorros de Empleados Públicos (2014).

${ }^{3}$ Barrera con Caja de Ahorros de Empleados Públicos (2014).

${ }^{4}$ Soissa con Caja de Ahorros de Empleados Públicos (2015).

${ }^{5}$ Soissa con Caja de Ahorros de Empleados Públicos (2015).
} 
En relación a lo decidido, concordamos que el derecho del trabajo se ha independizado del común, atendido que los paradigmas de ambas áreas difieren, por cuanto las relaciones entre empleadores y trabajadores no son equivalentes a las de los demás contratantes.

Sin embargo, cabría analizar si la desestimación de los principios civilistas puede llegar a la negación radical de la teoría de los actos propios en materia laboral, máxime si ella es más bien un reflejo de la buena fe que de la autonomía de la voluntad. Si bien el primero de estos principios tiene especial consagración en el derecho civil, posee ramificaciones en todas las áreas del derecho, considerándose un eje estructurante del sistema jurídico, que modaliza el ejercicio de los derechos de la relación laboral (Irureta U., P., 2010: 158). De forma que la sentencia peca al pontificar una doctrina totalizante en un terreno lleno de matices, por lo que consideramos que la decisión debió calibrarse con la aplicación de la buena fe en materia laboral.

Luego de esta aclaración, debemos examinar la sentencia y ponderar si la decisión fue la correcta. En la especie, ya vimos que la discusión versaba si el emolumento enterado era o no remuneración, debiendo sopesar que la trabajadora declaró en una escritura pública que ese pago no tenía tal calidad. Al respecto, el sentenciador del grado consideró que la conducta de la actora era contraria a la buena fe, debido a que quería aprovecharse "...de una situación fáctica que obviamente generaría beneficios en su favor, en circunstancias que durante toda su trayectoria adoptó una conducta acorde a los planteamientos que su empleador determinó...". 6

En este punto, corresponde analizar los antecedentes de hecho que fundaron los dichos del juez de la instancia. En efecto, consta que la prueba fundamental para el resolutor fue la declaración de la contadora de la demandada, que en un juicio distinto al que se pronunciaba, revalidó la posición de la empresa en la materia. Consideramos que sostener, con esa sola prueba, que la trabajadora había obrado de mala fe es extremadamente temerario, por cuanto admite sin más la tesis de la demandada, sin hacer otros distingos, ni considerar los descargos de la actora, como que fue presionada para firmar la declaración.

Con todo y haciendo abstracción de lo resuelto en la instancia, cabe preguntarse nuevamente si la sentencia de unificación, sólo con los antecedentes que contamos, desechó correctamente la teoría de los actos propios, aplicando el principio de irrenunciabilidad de los derechos.

En este punto, es pertinente definir qué se entiende por la teoría que aludimos. En efecto, cabe señalar que ella surgió del derecho civil para salvar situaciones contrarias al principio de la buena fe, postulando que no es lícito actuar de una manera completamente contrapuesta a la confianza generada a un tercero por una conducta anterior (Stitchkin L., D., 2009: 25-27). De dicha reflexión extraemos los elementos más importantes, esto es, la existencia de un sujeto que observe una conducta jurídicamente "relevante, inequívoca y eficaz" (Ekdahl E., M.F., 2009: 104), que posteriormente intente contradecir por medio de un derecho contrario, y un "tercero que modifique su propia situación, confiando en la conducta original del agente" (Ekdahl E., M.F., 2009: 104).

En nuestro derecho, la vigencia de esta doctrina no ha sido pacífica, por cuanto desde mediados de la década pasada nuestros tribunales han zigzagueado entre su aplicación y negación (Stitchkin L., D., 2009: 224). De igual forma, hay autores que consideran que no es posible

\footnotetext{
${ }^{6}$ Soissa con Caja de Ahorros de Empleados Públicos (2014).
} 
asimilarla, como el profesor José Luis Ugarte, quien refiere que esta teoría requiere la presencia de una conducta anterior jurídicamente eficaz, y que sólo puede emplearse cuando no exista solución legal, situación que no acontece en materia laboral, ya que su consagración infringe el artículo 5 del Código del Trabajo (Ugarte C., J.L., 2008: 91). Además, agrega que aplicar esta teoría implicaría movernos "en un sentido opuesto del principio de buena fe", pues aceptaríamos avalar la postura ilegal del empleador (Ugarte C., J.L., 2008: 92).

En tanto, la profesora María Cristina Gajardo considera que posiciones como la del profesor Ugarte llevarían, a lo menos parcialmente, a la incapacidad del trabajador para tomar sus propias decisiones (Gajardo H., M.C., 2010: 25), estimando que la citada teoría puede tener aplicación en nuestra área. Al respecto, distingue que la irrenunciabilidad laboral sólo puede asumirse frente a derechos efectivamente adquiridos y no ante meras expectativas (Gajardo H., M.C., 2010: 25). En este punto, incorpora la teoría de los actos propios, diferenciando el trabajador que justifica el cambio de su postura inicial, aludiendo y probando que fue víctima, por ejemplo, de vicios de su consentimiento al suscribir acuerdos lesivos a su condición, caso en el que nacería su derecho laboral irrenunciable, de quien no justifica esta situación, a quién podría aplicársele la polémica doctrina.

En una posición equidistante se pronuncia el profesor Alfredo Sierra, quien señala que no podemos variar la calificación jurídica de una situación fáctica (particularmente la existencia o no de una relación laboral), aludiendo a un acuerdo explícito entre las partes, máxime el principio de irrenunciabilidad (Sierra H., A., 2010: 144). Sin embargo, agrega que sería posible utilizar la teoría de los actos propios en casos en el vínculo laboral ha nacido y el trabajador incumplido sus obligaciones, imputando la falta a su empleador para así beneficiarse económicamente (Sierra H., A., 2010: 151).

De las posturas antes señaladas, creemos poder deconstruir la decisión de este caso. Para ello, debemos pronunciarnos primeramente del valor que le asignaremos a la escritura pública suscrita. En este punto, resulta importante destacar que el vínculo laboral ya se había iniciado, fluyendo todas las características que la configuran. En efecto, la subordinación ya es una realidad, tal como dependencia económica del trabajador en relación al empleador (Ermida U., O. y Hernández A., O., 2009: 275), elementos que nos son imposibles de olvidar al leer el tenor de la declaración. Al respecto, si bien el documento explicita una concesión en favor de la trabajadora, a reglón seguido dispone que no será incorporado como derecho a su contrato de trabajo, por cuanto será "...otorgado siempre que los excedentes así lo permitan en forma voluntaria y graciosa..." entendiendo asimismo, que no es una obligación jurídica de la empresa". Sobre el particular, podemos concluir que el empleador forzó, o al menos instó fuertemente su suscripción. Por otro lado, el documento fue signado especialmente para restarle valor jurídico laboral al pago de la denominada "gratificación", y así evitar que la trabajadora pudiera exigirlo compulsivamente. Situación evidentemente desbalanceada, en la que la menos fuerte se somete a la que lo es más, y obliga que el derecho del trabajo actúe.

De acuerdo a lo anterior, es plenamente aplicable lo referido por la profesora Gajardo, ya que podemos concluir que la trabajadora fue forzada por su posición desfavorable a suscribir el documento, situación que explica su aparente contradicción. De forma que es posible desechar la teoría de los actos propios en esta situación, ya que el supuesto obrar contrapuesto se encuentra plenamente justificado. 
Conforme a lo anterior, el principio de irrenunciabilidad se hace patente, máxime si el empleador pretendió negar a la trabajadora la titularidad de uno de sus derechos usando herramientas civiles. Así, es correcto que se pondere si el concepto de gratificación es o no remuneración, a la luz de lo que dispone el artículo 41 y 42 del Código del Trabajo, y no del tenor de la aludida escritura. Por ello, como en el caso concurren las consideraciones legales para considerarla como un haber laboral, debe incluírsela en el cálculo de las indemnizaciones que motivaron su desvinculación, pretensión que fundó la acción incoada.

Con todo, situaciones como la descrita nos hacen matizar aún más la aplicación de la teoría de los actos propios y ponderarla mejor, a diferencia de lo que hizo el sentenciador del grado, ya que en casos como éste es patente lo que indica el profesor Ugarte, en orden a que la mala fe no la encontramos en la conducta del trabajador, sino que en la del empleador que intenta sustraer artificiosamente del ámbito laboral un derecho de la parte más débil de la relación.

\section{BIBLIOGRAFIA.}

EKDAHL E., M.F. 2009 La Doctrina de los Actos Propios. El deber de no contrariar conductas propias. Santiago. Ed. Jurídica de Chile.

ERMIDA U., O. y Hernández A., O. 2009. Crítica a la subordinación. Revista español de derecho del trabajo $\mathrm{N}^{\circ} 116$.

GAJARDO H., M.C. 2010. Buena fe y derecho del trabajo. Revista Chilena de derecho del Trabajo y de la seguridad social. Vol. 1, $\mathrm{N}^{\circ} 2$.

IRURETA U., P. 2010. Vigencia del principio de la buena fe en el derecho del trabajo Chileno. Revista Ius et Praxis, año 17, $\mathrm{N}^{\circ} 2$.

SIERRA H., A. 2010. La Teoría de los actos propios en el ámbito laboral. Cuadernos de extensión de la Universidad de Los Andes $\mathrm{N}^{\circ} 18$.

STITCHKIN L., D. 2009. Estudio y análisis jurisprudencial de la aplicación de la Teoría de los Actos Propios en el Derecho del Trabajo". Memoria para optar al grado de Licenciado en Ciencias Jurídicas y Sociales. Santiago, Universidad de Chile Facultad de Derecho.

UGARTE C., J.L. 2008. Los actos propios en materia laboral o guía de como "inventarse una doctrina". Revista Laboral Chilena.

\section{JURISPRUDENCIA JUDICIAL CITADA}

"Soissa con Caja de Ahorros de Empleados Públicos", Excelentísima Corte Suprema, sentencia de 4 de agosto de 2014, (Recurso de unificación de jurisprudencia), Rol 24091-2014.

"Soissa con Caja de Ahorros de Empleados Públicos", Ilustrísima Corte de Apelaciones de Santiago, sentencia de 17 de marzo de 2014, (recurso de nulidad), Rol N 1333-2013.

"Soissa con Caja de Ahorros de Empleados Públicos", Ilustrísima Corte de Apelaciones de Santiago, sentencia de 21 de agosto de 2014, (recurso de nulidad), Rol N 410-2014.

"Soissa con Caja de Ahorros de Empleados Públicos", Primer Juzgado del Trabajo de Santiago, sentencia de 21 de febrero de 2014, (cobro de prestaciones), Rit O-4618-2013. 